\title{
CUADERNOS \\ AINTER.C.A.MBIO
}

SOBRE CENTROAMÉRICA Y EL CARIBE

Universidad de Costa Rica / CIICLA

\section{La poesía de la disidencia en la dictadura chilena: Raúl Zurita y Carmen Berenguer Eva Castañeda Barrera}

\author{
D0I: https://doi.org/10.15517/c.a.v16i1.36460
}

https://revistas.ucr.ac.cr/index.php/intercambio

\section{¿Cómo citar este artículo?}

Castañeda, Eva. (2019). La poesía de la disidencia en la dictadura chilena: Raúl Zurita y Carmen Berenguer. Cuadernos Inter.c.a.mbio sobre Centroamérica y el Caribe, 16(1), e36460. doi: https://doi.org/10.15517/c.a.v16i1.36460

Cuadernos Inter.c.a.mbio sobre Centroamérica y el Caribe

Vol. 16, No. 1, Enero-Junio, 2019 


\section{CUADERNOS \\ $\triangle$ INTER $\cdot$ C $\cdot A \cdot M B I O$}

Cuadernos Inter.c.a.mbio sobre Centroamérica y el Caribe

ISSN: 1659-0139

ISSN: $1659-4940$

intercambio.ciicla@ucr.ac.cr

Universidad de Costa Rica

Costa Rica

\title{
La poesía de la disidencia en la dictadura chilena: Raúl Zurita y Carmen Berenguer
}

\author{
Castañeda Barrera, Eva \\ La poesía de la disidencia en la dictadura chilena: Raúl Zurita y Carmen Berenguer \\ Cuadernos Inter.c.a.mbio sobre Centroamérica y el Caribe, vol. 16, núm. 1, 2019 \\ Universidad de Costa Rica, Costa Rica \\ Disponible en: http://www.redalyc.org/articulo.oa?id=476957940017 \\ DOI: https://doi.org/10.15517/c.a..v16i1.36460
}

Los autores/as que publiquen en esta revista aceptan las siguientes condiciones: 1. Los autores/as conservan los derechos de autor y ceden a la revista el derecho de la primera publicación, con el trabajo registrado bajo la licencia de atribución de Creative Commons, que permite a terceros utilizar lo publicado siempre que mencionen la autoría del trabajo y a la primera publicación en esta revista. 2. Los autores/as pueden realizar otros acuerdos contractuales independientes y adicionales para la distribución no exclusiva de la versión del artículo publicado en esta revista ( $p$. ej., incluirlo en un repositorio institucional o publicarlo en un libro) siempre que indiquen claramente que el trabajo se publicó por primera vez en esta revista.

Esta obra está bajo una Licencia Creative Commons Atribución-NoComercial-SinDerivar 3.0 Internacional. 
Página abierta

\title{
La poesía de la disidencia en la dictadura chilena: Raúl Zurita y Carmen Berenguer
}

\author{
The Poetry of Dissidence in the Chilean Dictatorship: Raúl \\ Zurita and Carmen Berenguer \\ A poesia da dissidência na ditadura chilena: Raúl Zurita e \\ Carmen Berenguer \\ Eva Castañeda Barrera ${ }^{1}$ evacbarrera@hotmail.com \\ Universidad Nacional Autónoma de México (UNAM), México
}

Cuadernos Inter.c.a.mbio sobre
Centroamérica y el Caribe, vol. 16, núm.
1, 2019

Universidad de Costa Rica, Costa Rica

Recepción: 03 Septiembre 2018

Aprobación: 29 Enero 2019

DOI: https://doi.org/10.15517/ c.a..v16i1.36460

Redalyc: http://www.redalyc.org/ articulo.oa?id=476957940017

Los autores/as que publiquen en esta revista aceptan las siguientes condiciones: 1. Los autores/as conservan los derechos de autor y ceden a la revista el derecho de la primera publicación, con el trabajo registrado bajo la licencia de atribución de Creative Commons, que permite a terceros utilizar lo publicado siempre que mencionen la autoría del trabajo y a la primera publicación en esta revista. 2. Los autores/as pueden realizar otros acuerdos contractuales independientes y adicionales para la distribución no exclusiva de la versión del artículo publicado en esta revista (p. ej., incluirlo en un repositorio institucional o publicarlo en un libro) siempre que indiquen claramente que el trabajo se publicó por primera vez en esta revista. CC BY-NC-ND
Resumen: El artículo examina las posibilidades del discurso poético para resignificar un hecho histórico, en este caso, la dictadura militar chilena (1973-1990). Nuestro objetivo central es analizar dos libros escritos durante el gobierno pinochetista, Canto a su amor desaparecido de Raúl Zurita (1985) y Huellas de Siglo de Carmen Berenguer (1986), con el fin de evidenciar que el discurso poético fungió como un espacio de resistencia y crítica frente al régimen militar. Para cumplir con este propósito, repasamos de manera general las distintas dicciones poéticas que existían en la década de 1980, al tiempo que revisamos el complejo contexto social al que se enfrentaron los artistas de la época. Posteriormente y con base en fuentes de la época y bibliografía especializada, profundizamos en las estrategias literarias que sigue cada una de las obras para nombrar el horror vivido durante la dictadura.

Palabras clave: Poesía, dictadura militar chilena, discurso, América Latina, memoria.

Abstract: The article examines the possibilities of poetic discourse to resignify a historical fact, in this case, the Chilean military dictatorship (1973-1990). Our main objective is to analyze two books written during the Pinochet government, Canto a su amor desaparecido by Raúl Zurita and Huellas de Siglo by Carmen Berenguer, in order to show that the poetic discourse served as a space of resistance and criticism against the military regime. To fulfill this purpose, we review in a general way the different poetic dictions that existed in the 1980s, while reviewing the complex social context faced by the artists of the time. Subsequently, and based on sources of the time and specialized literature, we delve into the literary strategies that each of the works follows to name the horror lived during the dictatorship.

Keywords: Poetry, chilean military dictatorship, speech, Latin America, memory.

Resumo: $\mathrm{O}$ artigo examina as possibilidades do discurso poético para resinificar um fato histórico, no caso, a ditadura militar chilena (1973-1990). Nosso objetivo principal é analisar dois livros escritos durante o governo Pinochet, Canto a su amor desaparecido de Raúl Zurita e Huellas de Siglo de Carmen Berenguer, para mostrar que o discurso poético serviu de espaço de resistência e crítica ao regime militar. Para cumprir este propósito, por um lado, revisamos de maneira geral as diferentes dições poéticas que existiram nos anos 80, por outro, examinamos o complexo contexto social enfrentado pelos artistas da época. Posteriormente, com base em fontes da época e bibliografia especializada, nos aprofundamos nas estratégias literárias que cada uma das obras segue para nomear o horror vivido durante a ditadura.

Palavras-chave: Poesia, ditadura militar chilena, discurso, América Latina, memória. 


\section{Presentación}

Los trabajos que se han escrito sobre la dictadura chilena son múltiples, y el abordaje suele hacerse desde distintas disciplinas como la historia, sociología, filosofía, artes plásticas e incluso los estudios culturales, entre otras. Todas estas aproximaciones, de una forma u otra y desde las herramientas que le son pertinentes, realizan un acercamiento a lo acontecido entre los años 1973-1990² . En ese sentido, la producción literaria en torno al tema es de suma importancia, pues la poesía, narrativa, además de los testimonios orales y las crónicas, se han convertido en una fuente valiosa de información, ya que en muchos casos de primera mano las víctimas narran historias que evidencian el maltrato al que buena parte de la sociedad civil fue sometida durante este cruento periodo.

Para efectos de este trabajo nos centraremos en dos obras poéticas que dan cuenta de la violencia producto de la dictadura en Chile. Nuestro corpus estará conformado por el libro Canto a su amor desaparecido (1985) del chileno Raúl Zurita (n. 1950) y por Huellas del siglo (1986) de la también chilena, Carmen Berenguer (n. 1946). El interés está puesto en profundizar en las estrategias literarias que siguen las obras analizadas para resignificar el hecho histórico (dictadura chilena); esto mediante la reflexión sobre el lenguaje de la poesía que se escribe en contextos de violencia. Se trata de problematizar las escrituras que a través de diversos recursos literarios representan el ejercicio de memoria-olvido y una resignificación del hecho histórico.

El acercamiento teórico a estos dos discursos poéticos lo haremos a partir de lo expuesto por la crítica argentina Josefina Ludmer, quien señala que:

Para poder entender este nuevo mundo (y escribirlo como testimonio, documental memoria y ficción), necesitamos un aparato diferente al que usábamos antes. Otras palabras y nociones, porque no solamente ha cambiado el mundo sino los moldes, géneros y especies en que se lo dividía y diferenciaba (Ludmer, 2009, p. 42).

Lo anterior supone una reflexión orientada a repensar los nexos entre la literatura, su entorno y las estrategias que el poeta utiliza para hacer efectivo ese vínculo.

Carmen Berenguer y Raúl Zurita pertenecen a una promoción de artistas y escritores que crearon y publicaron durante los años de la dictadura militar chilena, es por ello que se les ha llamado la generación de 1987, generación N. N., generación de la dictadura, entre otros. Este grupo heterogéneo dio cuenta, en el ámbito de la poesía, de una diversidad de tendencias que a todas luces se enfrentaba a una maquinaria cuya constante era la censura y represión. Valga señalar que las obras producidas en este periodo sentaron un precedente en Latinoamérica en cuanto a aspectos formales y temáticos se refiere, pues las escrituras producidas en contextos de violencia acuden a estrategias particulares para dar cuenta de una realidad fracturada:

El golpe militar no sólo significó la cancelación del proceso de cambio social que se venía dando desde mediados de la década de 1960 y con 
especial fuerza desde la ascensión de Allende al poder, sino que implicó una persecución a todos los agentes que pudieran incentivar directa o indirectamente el resurgimiento de dichas inquietudes, lo que llevó a una parte importante de los artistas intelectuales al exilio. Es fácil imaginar el panorama desolador que presentaba el país durante los largos setenta y gran parte de los ochenta. [...] No obstante, al pasar del tiempo y a pesar de lo que se pueda creer, los años posteriores al golpe fueron ricos en manifestaciones artísticas. [...] Las artes y la poesía se movieron desde el centro institucionalizado hacia una marginalidad plural, resistente e incontrolable para el aparato censor (Espinosa, 2008, pp. 17-18).

\section{Dicciones poéticas en el contexto de la década de 1980 en Chile}

Para una revisión de las distintas escrituras de la década de 1980 y años posteriores, es importante tomar en cuenta la diversidad de dicciones y preocupaciones estéticas. En ese sentido, retomamos la clasificación que hace el investigador chileno Iván Carrasco, quien establece cuatro grandes grupos temáticos relevantes que bien pueden orientar al lector sobre las líneas que la poesía de aquellos años fue adquiriendo progresivamente. Estas categorías son ${ }^{3}$ poesía neovanguardista, poesía religiosa apocalíptica, poesía comprometida y poesía etnocultural (Carrasco, 1989, p. 78).

La poesía neovanguardista se sitúa en el terreno del experimentalismo, además emparenta con las vanguardias tradicionales. De tal manera que la poesía de Raúl Zurita y Carmen Berenguer se inscribe en esta línea, ya que encontramos en su producción poética formatos con una propuesta de ruptura que incorpora el testimonio y otros géneros literarios como columna vertebral de la obra, además de un registro lingüístico que juega con la oralidad y la coloquialidad, la ruptura de la sintaxis será otro elemento importante. El caso paradigmático es uno de los libros aquí analizados, Canto a su amor desaparecido.

También en esta veta lírica encontramos las voces de Carlos Cociña, Tomás Harris, Eugenio Brito, Diego Maquieira, Elvira Hernández, entre otros. La tendencia de la poesía religiosa se proyecta como una continuadora de temas desarrollados por las grandes voces de la tradición poética chilena como Gabriela Mistral, Pedro Prado, Miguel-Arteche. "La sociedad y la crítica a una sociedad que, ya sea ecológicamente o a través de métodos de exterminio planetarios, ponen en peligro la supervivencia de la especie humana y del equilibrio del medio ambiente" (Morales, 2010, p. 18), son los temas esenciales de este grupo conformado por José María Memet, Armando Rubio Huidobro, Andrés Morales, Carlos Alberto Trujillo, por mencionar a los más representativos. La poesía comprometida es sin duda un espectro complejo, pues es conformada por un grupo heterogéneo y numeroso de escritores que abordaron de diversas formas temáticas de orden social. Valga decir también que el problema de la mayoría de los textos escritos bajo esta óptica es su evidente inmediatez, esto es, poemas que se circunscriben demasiado a un momento o a 
una situación en particular y que en términos estéticos no son lo suficientemente eficaces para trascender en el tiempo. La poesía en lenguas originarias es una manifestación reciente, pues no se había manifestado en la poesía chilena hasta la promoción de escritores que en este trabajo nos ocupa, esta tendencia es compartida por autores de orígenes indígenas que escriben en lengua mapuche y/o lengua castellana sobre las distintas visiones del mundo. Entre los poetas más representativos se encuentran las voces de Elicura Chihuailaf, Clemente Riedemann y Tomás Harris.

Nos enfrentamos entonces a un panorama heterogéneo en cuanto a estilos, aunque los temas y las preocupaciones de una u otra manera se vinculan, ya que hablamos de escritores que trabajan con la palabra a partir del desgarro colectivo provocado por el golpe militar en 1973. Así lo expresa Julio Espinosa Guerra:

[...] Por ello no es extraño que algunos hubiéramos comenzado a escribir en la prisión política o que parte de nuestro desarrollo se haya dado en el exilio eludiendo la represión con seudónimos o simplemente callando o postergando la publicación de nuestros textos. Éramos la generación NN: los sin nombre, lo que no existe, lo desaparecido. NN es una doble negación: Nunca nunca. Nadie nadie. De ahí soy. De allá somos (Espinosa, 2008, p. 26).

La producción poética de este periodo no se puede comprender sin los efectos del 11 de septiembre de 1973, ya que todos los órdenes de la vida fueron afectados por la dictadura que intentó mantener un control absoluto en la creación artística, esto con el propósito de eliminar cualquier expresión que fuera contraria al régimen. Valga señalar que en este trabajo revisaremos de manera general algunos de los episodios artísticos más importantes del periodo; momentos que incidieron y definieron el quehacer político y estético de los dos autores que aquí nos ocupan. El ámbito de las artes y la cultura atravesó circunstancias adversas que han sido llamadas el Apagón Cultural, un periodo caracterizado por la disminución de actividades artísticas en todos sus formatos: exposiciones de arte, circulación de libros y publicaciones, además de la censura informativa y de contenidos. No obstante, este esfuerzo de censura por parte de la dictadura, a finales de 1970, fueron múltiples las manifestaciones artísticas que buscaron caminos alternos para funcionar como rutas críticas al gobierno militar; ponemos por caso el surgimiento en 1978 de la revista La Bicicleta ${ }^{4}$ que buscó dar cuenta del quehacer artístico de las universidades y los distintos centros de producción artística de la época, esto incluía también a las comunidades civiles, además de que fungió como un medio de reflexión crítica en torno a la actividad social y cultural del país. Otros espacios valiosos en el terreno de las letras son los talleres Andamios, 666, Garage Matucana 19, La Unión de Escritores Jóvenes (ACU), revistas como el 100topiés, La Castaña, Huelén, La Gota pura, Postdata y el tríptico Envés, además de grupos literarios independientes como Aumen y Archipiélago.

Frente a un escenario tan complejo, los artistas de la época cuestionaron las formas tradicionales de hacer arte, por lo que exploraron formas alternativas y multidisciplinarias como el performance, el arte corporal, la relación entre la poesía, las artes visuales, y la fotografía. "Así se 
gesta un circuito no homogéneo de producción visual y escrita que proponía un lenguaje anti-institucional e indisciplinario sin antecedentes locales" (Reyes, 2012, p. 32). Esta "Nueva Escena" de artistas extiende su reflexión sobre el acontecer social y político a diversas disciplinas que, mediante elementos teóricos y prácticos, plantearon una manera diferente de nombrar la violencia imperante. Al respecto Reyes Sánchez señala que en torno a esta nueva manera de pensar la realidad, se conformaron tres núcleos más o menos nítidos de artistas y críticos:

1. En 1977 se conforma el grupo interdisciplinario V.I.S.U.A.L., compuesto por el filósofo Ronald Kay y los artistas Catalina Parra y Eugenio Dittborn, cuyo trabajo soportado por la galería Época, se distancia tanto de los circuitos comerciales como de la retórica del arte de izquierda militante.

2. Paralelamente a V.I.S.U.A.L., se formó otro núcleo compuesto por la crítica Nelly Richard y los artistas Carlos Leppe y Carlos Altamirano. [...] Los trabajos de este grupo recuperaron la fotografía, el video, la instalación y el uso del cuerpo. En un hecho inédito en tiempos de dictadura montan seis exposiciones, todas críticas a la hegemonía artística y orden social imperante.

3. En 1979 se formó el Colectivo Acciones de Arte (CADA) [...] quien reivindica las máximas vanguardistas de fusionar el arte con la vida y el arte con la política. [...] Sus objetivos formales estaban dirigidos a desmantelar el "aura" de la obra artística a favor de la acción y el proceso como trabajo de arte, mientras que sus objetivos políticos buscaban colaborar, interviniendo el espacio urbano y mediático, con la recuperación de la memoria, la comunidad y la articulación de resistencias contra la dictadura. Estaba conformado por dos artistas visuales: Lotty Rosenfeld y Juan Castillo, dos poetas: Raúl Zurita, Diamela Eltit y un sociólogo, Fernando Balcells quienes produjeron, con el apoyo de decenas de artistas, videoastas, fotógrafos, pilotos, organizaciones sociales y pobladores, nueve acciones de arte firmadas colectivamente entre 1979 y 1985 (Reyes, 2012, pp. 32-34).

Los proyectos $^{5}$ que surgieron a finales de la década de 1970 plantearon la posibilidad de explorar otras formas del discurso artístico en un contexto de violencia. Fue Nelly Richard quien en una revisión retrospectiva realizada en 1981, le puso un nombre a esta explosión de manifestaciones artísticas que por lo demás eran sumamente heterogéneas y disímiles. Así entonces, denominó Escena de Avanzada ${ }^{6}$ a las constelaciones de artistas que buscaron resimbolizar lo social fuera de las condiciones tan hostiles que los oprimían, esta resignificación abarcaba lo individual y lo colectivo en un escenario de censura y represión. Para conseguir este objetivo, los artistas apelaron a un desmontaje retórico y discursivo de las ideologías culturales del poder a través de la multidisciplinariedad, con especial énfasis en el cuerpo y en la ciudad 
como materias indóciles, además de que se planteó "la asunción del lenguaje como zona de peligrosidad" (Richard, 2007, p. 19) frente a la censura del dictadura militar. Las manifestaciones artísticas producto de este conglomerado de artistas apostaron por una estructura dinámica en donde las nuevas formas de discursividad replantearan los vínculos entre la esfera de lo artístico con la política. Así lo explicó Nelly Richard:

La "escena de avanzada”, hecha de arte, de poesía y literatura, de escrituras críticas, se caracterizó por extremar su pregunta en torno a las condiciones límites de la práctica artística en el marco totalitario de una sociedad represiva; por apostar a la imagen crítica como fuerza disruptora del orden administrado que vigila la censura; por reformular el nexo entre "arte" y "política" fuera de toda dependencia ilustrativa al repertorio ideológico de la izquierda sin dejar, al mismo tiempo, de oponerse tajantemente al idealismo de lo estético como esfera desvinculada de lo social y exenta de responsabilidad crítica en la denuncia de los poderes establecidos. Sin duda que la peculiaridad histórica de la escena de avanzada se debe a las circunstancias en las que formuló su productividad crítica. Escena que emerge en plena zona de catástrofe cuando ha naufragado el sentido, debido no sólo al fracaso de un determinado proyecto histórico, el de la Unidad Popular, sino al quiebre de todo el sistema de referencias sociales y culturales que, hasta 1973, garantizaba ciertas claves de entendimiento colectivo (Richard, 2007, pp. 15-16).

Frente a la violencia ejercida por la dictadura y en el contexto de la Escena de Avanzada, el caso de CADA es de los más significativos, pues a lo largo de seis años llevaron a cabo una serie de acciones que sirvieron para intervenir una ciudad de por sí ya intermediada por el régimen militar. Otro aspecto meritorio de este grupo fue que, a partir de su trabajo artístico, abrieron la posibilidad de que el ciudadano común pudiera participar de estas manifestaciones. De tal manera que la relación entre el arte y la ciudad ya no pasa, en las obras del CADA, por la tematización del acontecer popular bajo la forma de un relato, sino por la participación activa del sujeto en la resignificación contextual de las estructuras que atraviesan su cotidianeidad social y política. Así pues, el ciudadano interpela y dialoga acciones que en el contexto pinochetista eran inexistentes. En este sentido, Nelly Richard señala que el primer trabajo que se erigirá como un parteaguas para la escena de arte chileno que se desarrolla con posterioridad a 1979 es Para no morir de hambre en el arte, realizado por los artistas visuales Lotty Rosenfield y Juan Castillo, el sociólogo Fernando Balcells, el poeta Raúl Zurita y la novelista Diamela Eltit.

La primera obra se llamó Para no morir de hambre en el arte, en la que, junto con centros poblacionales, se repartió medio litro de leche como en la campaña de Salvador Allende y se sacaron camiones lecheros que se estacionaron frente al Museo Nacional de Bellas Artes y se armó una gran escultura social, mientras al mismo tiempo se emitía frente a la sede de las Naciones Unidas de Santiago un discurso grabado en los seis idiomas oficiales explicando lo que era para nosotros. Este discurso se llamó: "No es una aldea". Esta fue una manera de poder reseñar cuál era nuestra situación como artistas, como creadores y como habitantes de un país que estaba aislado, pero que había una voluntad de sobrevivir que empezaba a manifestarse (Zurita, 2018, pp. 97-98).

La investigadora Auli Leskinen señala que hoy podemos mirar el CADA como un "contradiscurso que se apartó de las estéticas 
referenciales del testimonio y de la protesta identificados con la izquierda y sus prácticas panfletarias. Evocaban temas urgentes como la carencia nutritiva e intelectual y la falta de libertades en la sociedad" (Leskinen, 2007, p. 139). Además de que este grupo puso en práctica la unión de la vida con el arte que, por lo demás, es uno de los principios de las vanguardias históricas, el estudioso de este periodo, Peter Burgüer, lo definió como praxis vital: "Esto se expresa, entre otras muchas formas, en la transformación del lenguaje, es decir, se busca un nuevo mecanismo que incorpore los elementos de la vida, de la cotidianeidad al arte" (Bürger, 1987, p. 45). En virtud de lo anterior, la participación de la sociedad civil fue un hecho fundamental para resignificar la ciudad, el cuerpo individual y colectivo, además de que mediante las diversas acciones de $\mathrm{CADA}^{7}$ se abrió la posibilidad de que existiera un diálogo entre los ciudadanos y su entorno.

La producción artística de la Escena de Avanzada es sin duda un referente en la historia de Chile y de América Latina, pues las aportaciones e innovaciones en el terreno de las artes visuales, la fotografía, el performance, la literatura, entre otras, son incuantificables. No obstante, para efectos de este trabajo nos centraremos en el discurso poético, el cual, al igual que las otras expresiones, hizo las veces de un espacio de disidencia frente a la dictadura militar. Por una parte, el gesto meritorio de surgir y sostenerse a pesar de que las condiciones históricas y sociales no favorecían la existencia de manifestaciones que fueran críticas al régimen. En segunda instancia, numerosos escritores evidenciaron su posición política a través de obras que acudían a formas y medios alternativos, lo que quiere decir que la represión y la censura orillaron a los artistas de la época como Raúl Zurita ${ }^{8}$ y Carmen Berenguer a pensar su quehacer poético desde otras rutas. De tal forma que, como arriba lo enunciamos, la formación de grupos, talleres, colectivos de arte, revistas y el trabajo individual de numerosos artistas se vuelve un referente fundamental durante el gobierno de Augusto Pinochet, ya que en su mayoría estos artistas optarán por modos de enunciación polisémicos, oblicuos, indirectos, polifónicos y fragmentarios que planteaban un desafío al discurso dictatorial. Así lo señala María del Refugio Morales sobre la escritura política escrita en la dictadura:

En un contexto como la dictadura, los discursos del arte y la cultura van a trabajar con un modelo formalmente opuesto al discurso autoritario: el de la pluralidad de sentidos. Si el discurso de la dictadura cierra la circulación de los significados, los discursos literarios proponen una práctica de sentidos abiertos. [...] El discurso de la ficción se coloca formalmente como opuesto al monólogo practicado por el autoritarismo, de tal manera que la literatura de la dictadura se detiene y explora la respuesta a la pregunta ¿cómo contar el horror vivido? (Morales, 2010, p. 47).

\section{Raúl Zurita: el lenguaje de la poesía frente a la dictadura}

Raúl Zurita es hoy en día un referente obligado para la poesía chilena y latinoamericana en general, su obra poética se circunscribe mayoritariamente a la experiencia de la dictadura militar. No obstante, 
también conecta con las múltiples historias de agravio y vejación que muchos de los países latinoamericanos viven, especialmente aquellos que han sido víctimas de regímenes dictatoriales. La reflexión que ha guiado la escritura del poeta chileno está marcada indefectiblemente por las vivencias dolorosas de la violencia.

El poeta chileno se aleja de la poesía política y en su lugar acude a formas que rebasan por mucho la discursividad tradicional. Por ejemplo, su necesidad de protesta frente a la dictadura lo llevó a realizar una serie de actos que podrían calificarse desde desmesurados a cuestionables: quemarse los ojos con amoniaco y la mejilla con un hierro ardiente, escribir en el desierto de Atacama o en el Cielo de Nueva York son algunas de las acciones que evidencian "que el discurso lírico debe montarse sobre nuevos soportes materiales. [...] Zurita no cree que la poesía pueda ser factor de transformación social, pero está convencido que su presencia en el mundo es absolutamente necesaria" (Aguilera, 2012, p. 79). Amén de los ejemplos señalados, es cierto que no toda su obra excede los límites textuales, sin embargo, estas prácticas resultan ser evidencias contundentes de su poética y por tanto de la manera, excesiva si se quiere, de entender el acto creativo. Así lo expresa el propio Zurita:

Desde el momento en el que la propia dictadura se llamó a sí misma "gobierno autoritario" hay una pelea en el terreno concreto del lenguaje. El lenguaje es la primera zona, el primer terreno de la lucha. Una vez instalada la dictadura, lo primero que hace es precisamente tratar de dar un nuevo sentido a todas las palabras, además de concebir la historia de Chile y una manera de lanzar héroes a la palestra (Zurita, 2018, p. 85).

Esta disputa en lo que él llama el terreno concreto del lenguaje, se dirimió mediante formas alternativas, rutas que los artistas de la Escena de Avanzada habían puesto en marcha. En ese contexto la posición estética era también política, por lo que frente al monólogo de la dictadura había que poner en práctica una escritura que preservara el recuerdo de aquellos cuerpos que habían sido torturados y más tarde desaparecidos; la poesía para Zurita no es contemplación pasiva, su tarea, si es que puede asignársele una, es la recuperación de la memoria. De tal manera que poesía y memoria invitan a pensar al otro desde su particularidad para luego abarcar el cuerpo social, "la relación individualidad y colectividad se pone en juego a partir del cuestionamiento del ser humano consigo mismo y frente al otro. El otro es atravesado por la palabra del poeta. En la memoria prevalece la memoria de ese otro" (Villegas, 2007, p. 69).

Así pues, el libro que aquí nos ocupa, Canto a su amor desaparecido, versa sobre el sufrimiento individual y colectivo producto de la violencia, tortura y desaparición de cientos de miles de personas durante la dictadura militar chilena. Sin embargo, no solo se restringe a ese doloroso tema, aborda también la desventura política y social en que buena parte de Latinoamérica está sumida. El título mismo nos advierte que estamos frente a un Canto que en términos temáticos guarda relación con el treno ${ }^{9}$, Zurita canta en sentido moderno a las personas y a los países que han sido víctimas de la persecución y represión, lo hace desde el desencanto y desde la conciencia que le da ser un sobreviviente: 
El canto a su amor desaparecido es parte de una pesadilla. [...] Yo entiendo esta obra como una apertura nuestra al vislumbre del porvenir. Ahora, en un país, Chile, o en países como los nuestros, donde hay tantos desaparecidos, donde suceden tantas cosas diariamente, todos los que hablamos lo hacemos seguramente en calidad de sobrevivientes. Entonces nuestra palabra siempre está cargada, sepámoslo o no, de esta condición de sobrevivencia (Zurita, 2018, p. 76).

Los versos inaugurales son descriptivos del tema que se desarrollará a lo largo del libro: "Ahora Zurita -me largó- ya que de puro verso y desgarro pudiste entrar aquí, en nuestras pesadillas; ¿̇ú puedes decirme dónde está mi hijo?” (Zurita, 1985, p. 204). El sujeto poético manifiesta que Zurita le ha expulsado, le ha pedido que se marche, advierte que es a través de la poesía como práctica desgarradora que ha podido penetrar al terreno de lo sórdido. El uso del plural en los versos nos indica que la colectividad vive el horror de una situación marcada por la violencia. La interrogante que se muestra como cierre de los versos es lapidaria: “¡tú puedes decirme dónde está mi hijo?”. Al formular esta pregunta, la voz poética entrega al lector un panorama de desolación porque se evidencia que alguien no está, un hijo ha desaparecido y el que busca -en este caso un padre-ignora su paradero. Una estrategia muchas veces utilizada por el poeta chileno es el desdoblamiento de la voz poética, de tal manera el autor se implica en el discurso. Raúl Zurita es el autor y también el sujeto lírico que da cuenta del horror de la dictadura que, por lo demás, ha sido el tema que ordena toda su producción literaria: "La dictadura y el golpe militar en Chile es el hecho más crucial de mi vida, más crucial que la muerte de mi padre cuando yo tenía 2 años. Nunca saldé eso. Es lo que me ha marcado definitivamente" (Zurita, 2018, p. 76).

Canto a su amor desaparecido está dedicado a los chilenos, a las mujeres argentinas que durante la dictadura de Jorge Rafael Videla perdieron a sus hijos, a las cientos de familias que cuentan las historias de sus desaparecidos, a los torturados y a los países, incluyendo a Chile, que han sido partícipes de todas estas masacres. El lector en este punto puede apreciar con claridad que el libro será un canto a la ausencia y a la violencia política y social en Chile y Latinoamérica:

- A la Paisa

- A las madres de la plaza de mayo

- A la Agrupación de Familiares de los que no aparecen

- A todos los tortura, palomos del amor, países chilenos y asesinos (Zurita, 1985, p. 10).

El poema inicia en primera persona: "canté, canté de amor". A medida que el texto avanza, una descripción casi mortuoria se presenta al lector y mediante una narración que por momentos se torna alucinante, las distintas voces poéticas van enhebrando un discurso que da cuenta de una realidad lúgubre:

[...] Canté la canción de los viejos galpones de concreto. Unos sobre otros decenas de nichos los llenaban. En cada uno hay un país, son como niños, están muertos. Todos yacen allí, países negros, áfrica y sudacas. Yo les canté así de amor la pena a los países. Miles de cruces llenaban hasta el fin el campo. Entera su enamorada cante\# así. Cante\# el amor: (Zurita, 1985, p. 11). 
El primer espacio físico que se presenta en el poema son los galpones de concreto y dentro de ellos hay decenas de nichos que son ocupados por países que la voz poética compara con niños muertos, lo que potencia la idea de indefensión y debilidad; valga señalar también que las expresiones "países negros y sudacas" son considerados despectivos, en tanto apuntan a la descalificación del otro. Son marcas lingüísticas que indican racismo e incluso xenofobia. Al respecto Yovany Salazar sostiene que, "ahora se encuentra ante nosotros la profundamente perturbadora cuestión de nuestra relación con los otros. [...] otros territorios, otras geografías, otras culturas" (Salazar, 2015, p. 27). No es gratuito que Zurita haga mención de espacios que históricamente han sido violentados (países negros, áfrica y sudacas), el poeta chileno nombra la transgresión y mediante imágenes poéticas traza una arquitectura signada por la muerte, de ahí que los galpones estén ocupados por nichos con países que semejan niños muertos.

En términos formales, la narratividad exacerbada del texto permite que distintas voces confluyan, aunque por momentos y de manera un tanto abrupta, una voz se diluye para dar paso a otra, lo cual genera un juego coral que abre nuevos significados. Por una parte, identificamos la voz de un torturado, más tarde irrumpe la voz de una enamorada que le habla a su amado (ambos están muertos) y en medio aparece una voz que evoca a alguien que estaba entre los torturados y que ha desaparecido. De esta manera, el libro es la visión del sufrimiento durante la dictadura y cada uno de los personajes la enuncia desde su particular pérdida. En estos fragmentos habla la voz poética del torturado:

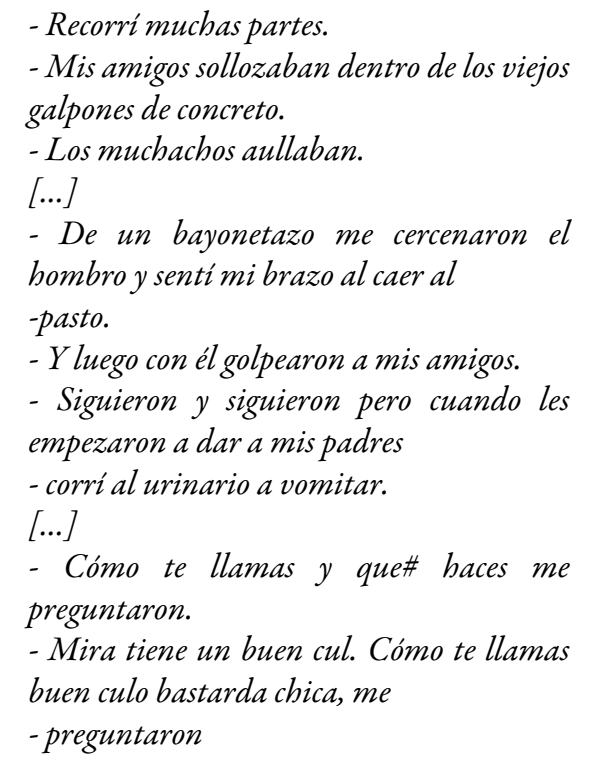

Fuente: (Zurita, 1985, p. 13).

El Estado autoritario que se conformó en Chile a partir de 1973 anuló todo principio de representación democrática, de tal manera que la represión se expresó, tanto en la nueva Constitución como en las demás leyes decretadas por la Junta militar. No existió contrapeso jurídico alguno, por lo que la estructura represiva quedó en manos de una minoría 
organizada en torno a la fuerza material. El abuso de la fuerza física y la sistemática violación de los derechos humanos durante toda dictadura es la prueba fehaciente del poder desmedido del gobierno hacia sus ciudadanos ${ }^{10}$. Los versos de Zurita dan cuenta de ello, "de un bayonetazo me cercenaron el hombro y sentí mi brazo al caer / al pasto / y luego con él golpearon a mis amigos / siguieron y siguieron pero cuando les empezaron a dar a mis padres" (Zurita, 1985, p. 13). En virtud de ello, el lenguaje ofensivo revela el desprecio al otro, al que ha sido privado de su libertad y dejado a merced de aquel que posee la superioridad material y física: "Mira tiene un buen cul. Cómo te llamas buen culo bastarda chica, me / preguntaron" (Zurita, 1985, p. 13). Mediante una adjetivación agraviante se priva al sujeto de su identidad, las palabras son usadas para demostrar supremacía sobre el cuerpo del interlocutor. El Golpe como acontecimiento histórico tuvo también una importante dimensión simbólica, pues el espacio público y el lugar del diálogo fueron cancelados. Sirva como ejemplos lo señalado en los puntos 4 y 5 del Primer comunicado de la Junta militar: "la prensa, radios difusoras y canales de televisión adictos a la Unidad Popular deben suspender sus actividades informativas a partir de este instante. De lo contrario recibirán castigo aéreo y terrestre. El pueblo de Santiago debe permanecer en sus casas a fin de evitar víctimas inocentes" (memoriachilena Biblioteca Nacional de Chile, s. f./b, párr. 5).

El discurso de la dictadura establece los parámetros de orden que la sociedad civil debe seguir, pero también el silencio tenía un significado relevante, dado que era en algún sentido la medida más absoluta porque sus vacíos permiten el abuso de poder; Lilian Zac, apunta que "en un contexto donde nadie sabía muy bien quién era un pecador, el silencio se suponía debía ser total. De esta manera, la condición de subversivo podía aplicar a cualquier persona en cualquier lugar" (Zac, 1995, p. 85) y eran los militares los que en última instancia podían identificar a los elementos sediciosos y terminar con aquella amenaza. En Canto a su amor desaparecido, los sujetos poéticos del libro atraviesan el horror de la dictadura militar, todos son sospechosos, y por ello víctimas potenciales de la violencia. La vejación física y emocional, la censura y el silencio y el monólogo del poder absoluto que anula las palabras de los más débiles son los temas del libro. No obstante, como el mismo título del libro lo advierte, el amor también ocupa un lugar en esta geografía de la desolación; una de las voces poéticas del texto pertenece a una mujer muerta que le habla a su también fallecido amante, ambos son víctimas y testigos de la violencia:

\footnotetext{
Me derrumbe\# a tu lado creyendo que era

yo la que me arrojaba.

El pasto estará creciendo me imagino.

En verdad me gustan más las piedras creí

no, el pasto.

Crei que eras tu\# y era yo.

Que yo aún vivia, pero al irme sobre ti algo

de tu vida me desmintió.
} 


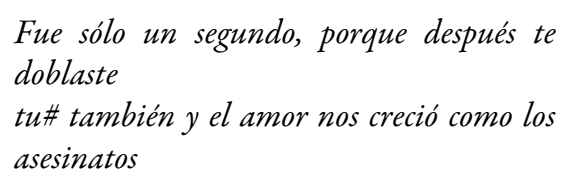

Fuente: (Zurita, 1985, p. 14).

La sensación de caída en el poema se presenta en dos sentidos, en principio, los verbos "derrumbé", "arrojaba" y "doblaste” enfatizan la trayectoria del descenso. Por otra parte, la actitud dubitativa de la voz poética refuerza las imágenes que proyectan a los amantes hacia la muerte: "Me derrumbé a tu lado creyendo que era yo la que me arrojaba", la amante desea tomar el lugar de su enamorado porque su amor la motiva a hacerlo, su deseo es librarlo del sufrimiento. Si bien aquí se expresa un amor carnal, no es el único que prima en el poemario, la creencia en el amor al otro atraviesa el libro entero; este tópico encuentra sustento en la tradición cristiana, misma a la que el poeta chileno acude constantemente para hacer referencia en su obra poética. Recordemos que en La Biblia se expresa el mandato de amar al otro por sobre todas las cosas: "amarás a tu prójimo como a ti mismo", Zurita retoma esta idea y la resignifica en un contexto de sufrimiento y muerte: "-Murio\# mi chica, murio\# mi chico, desaparecieron todos. / Desiertos de amor" (Zurita, 1985, p. 15).

En Canto a su amor desaparecido también nos encontramos con una propuesta visual que es inaugurada por el apartado "Galpones 12 y 13 en párrafos se lee y dice”. Raúl Zurita hace la representación visual de los nichos a partir de fragmentos que están dispuestos de tal forma que simulan las formas cuadradas de los nichos mortuorios. La voz poética enuncia que alguien hace un recorrido de "nicho tras nicho, fosa tras fosa, buscando los ojos que no encuentra. De la\#pida en la\#pida, de lloro en lloro, por nicheri\#as" (Zurita, 1985, p. 16). A partir de este punto, el sujeto lírico buscará a las cientos de miles de personas que fueron desaparecidas y asesinadas durante la dictadura. En cada uno de los nichos se inscribe una breve ficha alusiva al país. Así por ejemplo, en el espacio correspondiente a Argentina, se lee: "De tortura en tortura, desaparecimiento y exterminio quedó hueca como los países nombrados, y la noche no tuvo donde caer ni el día" (Zurita, 1985, p. 18). El fragmento hace referencia a la dictadura militar en dicho país y Zurita de manera breve y contundente expone, mediante los sustantivos tortura, desaparecimiento y exterminio, el horror vivido durante ese periodo. La misma estrategia descriptiva es aplicada a los nichos correspondientes a Estados Unidos, Amazonas, Perú, África, Colombia, Paraguay, Haití, México, Nicaragua, Guatemala, Angola, Venezuela, Canadá, Bolivia, El Salvador, Cuba, Ecuador, Uruguay y finalmente Chile. Aunque para referirse a este último, la voz poética se extiende un poco más:

\footnotetext{
¿Llamai tumba del amor de los paises? ¿Por duelo me llamaste? ¿Por puro duelo fue? ¿Por duelo fue el amor que lloraron tanto? Que tanto me iban diciendo que se acaba, que se acaba todo y fue el
} 


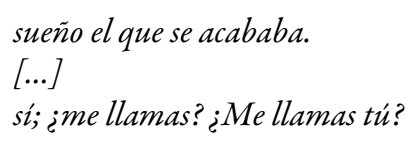

Fuente: (Zurita, 1985, p. 23).

Mediante una serie de interrogantes la voz poética acentúa la sensación de pérdida y tristeza, ya que, llegado a este punto, el libro ha trazado los planos de una necrópolis que rebasa por mucho a Chile para hacerse extensiva a todo el mundo, pues de manera global nichos y fosas guardan historias de vejación y miseria. La atmósfera de desolación y pérdida se ve reflejada en la repetición del sustantivo "duelo”: “¿por qué duelo me llamaste? / ¿pero puro duelo fue? ¿por duelo fue el amor que lloraron tanto?" (Zurita, 1985, p. 24). Sobre este tema, Sergio Carlos Staude en su artículo "El duelo: sus recursos", señala que: "el inicio de un duelo abre las puertas a una tierra de nadie. El sujeto se desconoce, o queda inmerso en una confusión dolorosa. No hay otro simbólico, no quedan sostenes fantasmáticos" (Staude, 2011, p. 194). En ese sentido, y apelando a lo espectral, la voz poética afirma que todo ha concluido en un espacio de absoluta desesperanza frente a la pérdida y el dolor que ocasiona la ausencia de aquellos que la dictadura ha hecho desaparecer.

En la parte final del libro, y para continuar con los elementos visuales, Zurita agrega dos dibujos que hacen las veces de mapas, en estos se señala la ubicación concreta de cada uno de los nichos en los que descansan los países muertos. A estos mapas les sigue lo que será el poema final del libro, "Canto de amor de los países", aquí un fragmento:

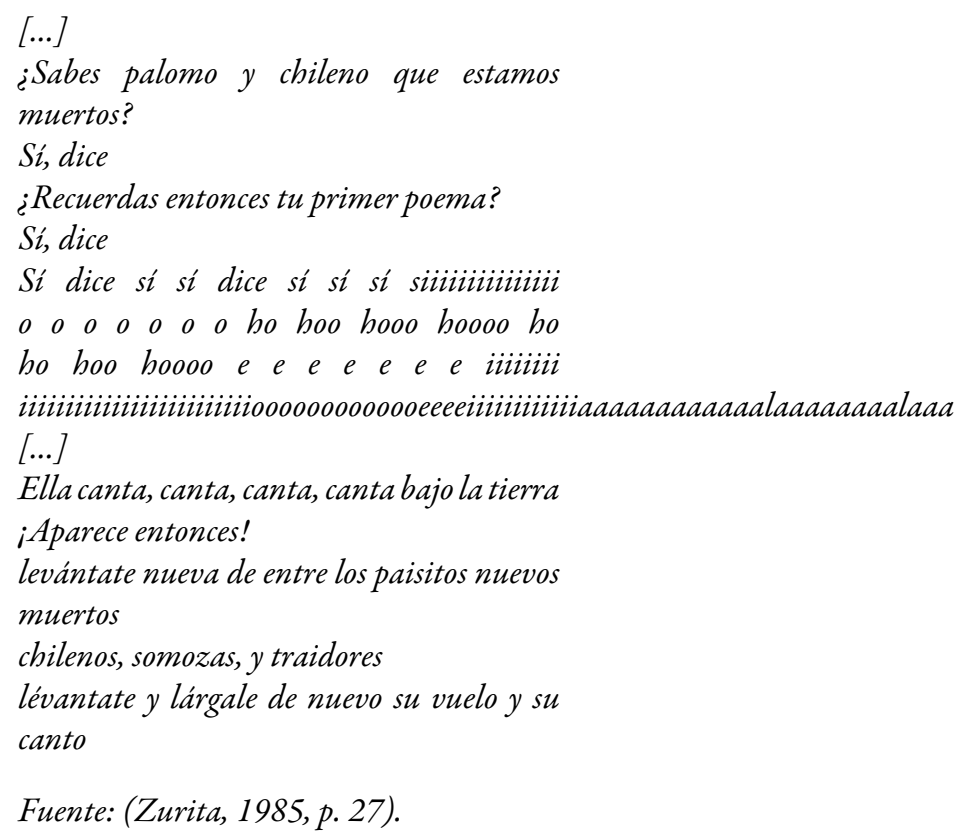

Canto a su amor desaparecido es un libro que a partir del lenguaje poético resignifica un hecho traumático para la historia de un país y de una continente; además de que es un reconocimiento simbólico de las víctimas del sufrimiento provocado por la violencia de regímenes políticos autoritarios, en este caso específico, la dictadura chilena. Representa 
también un modo particular de preservar las memorias del pasado reciente, mediante una serie de estrategias formales que suponen....

\section{Carmen Berenguer y el cuerpo público de la escritura poética}

Carmen Berenguer también se inscribe en una línea poética que reflexiona sobre el ejercicio escritural desde un horizonte particular, su propuesta poética es una combinación de opinión política y crítica cultural con especial énfasis en las relaciones entre género, cuerpo y lenguaje. Sus primeros libros fueron escritos y publicados durante la dictadura en ediciones de circulación restringida. Tal es el caso, por ejemplo, de su primer libro, Boby Sand desfallece en el muro (1983), que fue considerado en el momento de su publicación como "un gesto de provocación política, dado que se publicó en plena dictadura militar, momento en el que había que pedir permiso al ministerio del Interior para hacerlo" (Faundes, 2014, p. 36). Así pues, su obra poética evidencia un compromiso social que desde el inicio de su trayectoria se hizo manifiesto, además de que se suma a la poesía femenina de denuncia y resistencia frente a la represión pinochetista. La poeta chilena no se ciñe en estricto sentido a la noción tradicional de poesía, hay en su escritura un constante desplazamiento a otras formas literarias e incluso una mezcla de géneros; estas búsquedas resultan significativas sobre todo si las pensamos en el contexto de la dictadura. Berenguer en ese sentido, se inscribe en una genealogía de creadores que sentaron las bases de una práctica literaria politizada y crítica que ponía en el centro de su preocupación la exploración de nuevas rutas artísticas.

Huellas de siglo se publica en un Chile signado por la censura y la represión, es el segundo libro de Carmen Berenguer y, valga decirlo, seguirá la misma ruta del primer poemario ${ }^{11}$. Es decir, abreva de ciertos hechos históricos para proyectar una crítica mordaz y sin ambages al Chile pinochetista. La primera sección se titula "Santiago Punk" y mediante una serie de paralelismos sintácticos, fonéticos y sonoros, la autora enhebra un lenguaje poético que emula los ruidos de una ciudad, que a pesar del retraso en términos de derechos humanos, quiere alcanzar el crecimiento económico ${ }^{12}$. "Punk, Punk / War. War. Der Krieg, Der Krieg / Bailecito color obispo / La libertad pechitos al aire / Jeans, sweaters de cahemira / Punk artesanal made in chile / Punk de paz" (Berenguer, 2018, p. 57). Si la poesía de Zurita se concentra mayoritariamente en el sufrimiento existencial de las víctimas de la dictadura; la escritura de Berenguer reflexiona políticamente sobre tres aspectos que serán la columna vertebral del libro. Por una parte, el crecimiento de Santiago como una urbe que se perfilaba a la aparente modernidad en la década de los ochentas, el otro tópico será los cuerpos (femeninos sobre todo) y por último, que no menos importante, toda la violencia que atraviesa los aspectos anteriores.

El imaginario de la ciudad que urde Berenguer se construye a partir de "una exploración y uso de las posibilidades referenciales, simbólicas y alegóricas del lenguaje, recorriendo y yuxtaponiendo vetas testimoniales, 
coloquiales, barrocas y góticas del discurso poético" (Del Valle, 2001, p. 78). Este lenguaje evidencia una estrategia estética y política que penetró con fuerza en la escritura del periodo de la dictadura en Chile. En Huellas de siglo se recrean las múltiples escenas de violencia en la ciudad de la dictadura pinochetista. Así lo ejemplifica el poema que lleva por título "Molusco":

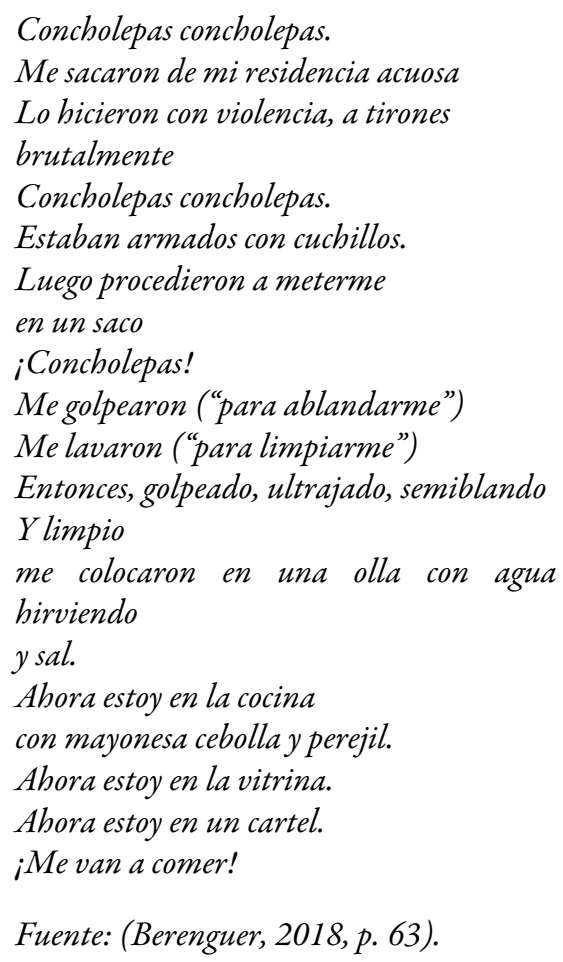

La concholepa es un molusco comestible muy conocido en Chile al que de manera local le llaman loco; Berenguer lo toma como tema y apela a la metonimia para construir un poema que de fondo habla sobre los desaparecidos y torturados. La violencia a la que es sometido el molusco es descrita desde que de manera disruptiva alguien penetra en su concha para extraerlo, hasta que este es cocinado y luego servido para el consumo humano. En ese sentido, el símil con el contexto de la dictadura es exacto, pues muchos de los sobrevivientes narran en sus testimonios que fueron sacados por la fuerza de sus casas para después ser llevados a centros de tortura, en el texto la voz poética dice: "Me sacaron de mi residencia acuosa / Lo hicieron con violencia, a tirones / Brutalmente" (Berenguer, 2018, p. 63). La recreación de un hecho cotidiano durante el régimen militar es hecha a partir de un registro cotidiano, evocando una situación aparentemente doméstica y sin importancia, lo cierto es que mediante las estrategias literarias adecuadas, Berenguer denuncia un hecho brutal y lastimoso en la vida de un país: "Me golpearon ("para ablandarme") / Me lavaron ("para limpiarme") / Entonces golpeado, ultrajado, semiblandon / Y limpio / Me colocaron en una olla con agua hirviendo / Y sal" (Berenguer, 2018, p. 63). La autora indirectamente hace referencia a la tortura, misma que en los años de 
dictadura, fue un método de control por parte del Estado en donde el cuerpo era sometido a múltiples violencias:

La coacción de los cuerpos y el sometimiento de e\#stos, fue un secreto a voces durante el régimen militar que se extendió en Chile. La dictadura marco\# una etapa negra compleja en la historia local y regional. [...] Las garantías de las personas estuvieron vinculadas y entrelazadas con el derecho y la disciplina de los propios cuerpos, que en mayor o menor medida esta\# condicionado en este paradigma por una acción catastrófica, ya sea ésta simbólica o palpable (Osorio, 2012, p. 241).

En "Molusco", uno de los poemas más crudos del libro, queda evidenciada la transgresión del cuerpo: "Ahora estoy en un cartel. /iMe van a comer!” (Berenguer, 2018, p. 63), la mención al cuartel evidencia de manera clara y directa un episodio que fue sistemático en los años que van de 1973 a 1990 en Chile, y que en la mayoría de los casos el final de las personas que era detenidas, llevadas a un cuartel y luego torturadas, era la muerte. Así se construyó una historia de desapariciones y represión, pero la poesía irrumpe en ese escenario para dejar constancia de ello, para preservar la memoria de una serie de hechos vergonzosos y ominosos; lo hace desde un lenguaje opuesto al de la violencia porque "la violencia habla un lenguaje opaco, que llama la atención sobre sí mismo, que no busca la transparencia del intercambio comunicativo, se agota en su empecinada y onanista performatividad" (Moraña, 2014, pp. 331-332). En virtud de ello, Berenguer acude a lo largo del libro a un registro coloquial para transparentar las escenas más sórdidas en un contexto de represión, "Ha muerto Manuel / y Manuel se levanta / impresa su hoja en la orilla” (Berenguer, 2018, p. 80), por las páginas de Huellas de siglo transitan personajes que habitan una ciudad sitiada y su lenguaje es el de todos los días, es decir, la jerga cotidiana, "Virgencita del Carmen / patroncita del ejército", "Bailecito color obispo", "tanguito revolucionario", "Patitas de chancho / caldo de cabeza" (Berenguer, 2018, p. 57).

El lenguaje es una toma de partido frente a la realidad, es también un espacio de crítica y creación, por ello el discurso poético de la chilena es un acto consiente y deliberado, no hay lugar para el azar o la contingencia. El fragmento inaugural de la sección titulada "Huellas del siglo", apunta: "La química sirve para todo, / hasta para borrar manchas históricas" (Berenguer, 2018, p. 87). El lugar de enunciación de estos versos es como arriba quedó señalado, un país atravesado por el autoritarismo y la violencia, por ello la voz poética dice, "manchas históricas" y de inmediato le da un giro a la interpretación cuando irónicamente afirma que las manchas históricas pueden ser borradas por la química. El señalamiento a una serie de hechos ominosos es evidente; sin embargo, al introducir la ironía como una estrategia literaria, da una dimensión distinta al texto, pues no solo nos encontramos frente a una afirmación sobre la historia, sino que además estamos frente a una actitud que denota, por parte del sujeto poético, una comprensión cabal de su entorno o de su contexto histórico. Es decir, estamos frente a una experiencia vital. 
La última sección del libro titulada "Lengua osa verba" se compone de un poema que lleva el mismo título, encontraremos que el juego con la sonoridad será la constante, además de que la mezcla entre coloquialidad y oralidad enhebrará un texto aparentemente inconexo y en cierto sentido delirante:

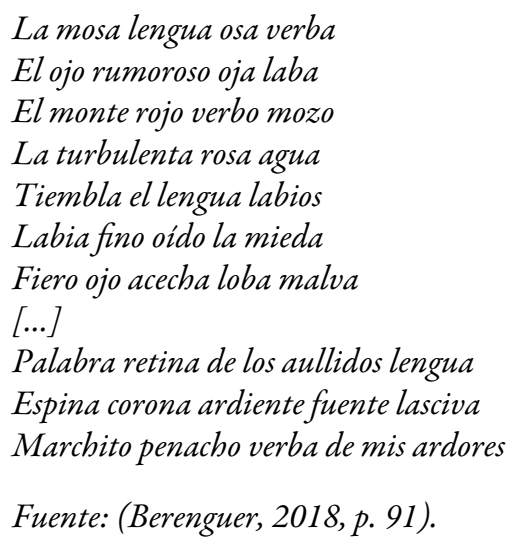

En "Lengua osa verba" las palabras se aglutinan y la sintaxis se trastoca para generar un nuevo significado, la escritura "carga una respuesta política pujando por un habla libertaria y rebelde ante la invasiva lógica de la ciudad dictatorial en el Chile de Pinochet" (Cárcamo, 2016, p. 76). No obstante, hay también un fracaso anunciado en los versos finales del poema cuando señala "Marchito penacho verba de mis ardores", en donde el adjetivo marchito otorga un significado que asociamos con la idea de lo muerto, lo vencido. Este último poema es representativo de una búsqueda por parte de la autora para llevar al lenguaje y a la palabra por derroteros distintos a los de la poesía tradicional, valga decir que estas búsquedas y hallazgos los hace en un contexto histórico que resulta hostil, no obstante esas misma condiciones motivaron nuevas formas de relacionarse con las palabras, pues frente al discurso autoritario y unilateral de la dictadura, los caminos de la creación y por tanto del lenguaje, debían ensancharse.

En relación con lo anterior, las lecturas públicas de Carmen Berenguer son también otro aspecto digno de resaltarse, pues muchos de sus poemas los lee en voz alta atendiendo a una serie de particularidades que la sitúan en un lugar distinto al de una lectura de poesía tradicional. Berenguer lee sus poemas como un acto performático. Es decir, voz, cuerpo, espacio físico y escuchas, le dan al poema una dimensión distinta que configura lo que algunos críticos han dado en llamar el cuerpo público de su escritura poética. El carácter de público o colectivo es un aspecto de suma importancia si recordamos que:

En el Chile bajo dictadura, y particularmente entre fines de los setenta y el curso de los ochenta, la lectura de las o los poetas no sólo se acotó al acostumbrado ritual del recital poético, sino que asimismo era requerida en eventos del movimiento social y político por la democracia. [...] En las experiencias de dicho ajetreo político Berenguer fue fraguando una incorporación y cultivo constante de la voz y la performance acústica y pública de sus textos (Cárcamo, 2016, p. 79).

Huellas de siglo representa un posicionamiento claro de la escritura poética de Berenguer, además de que constituye una estética y una política 
del lenguaje. La aportación de este libro a la poesía de los años ochenta del siglo pasado es valiosa, en tanto contribuye a la emergencia de la escritura de mujeres y pone en la reflexión al escenario citadino como un espacio atravesado por la violencia y la represión. Su performance literario es otro hecho digno de destacarse, ya que otorga al poema una existencia que rebasa los límites de la hoja y se sitúa frente a una colectividad que en los años de dictadura estaba ávida de escuchar un lenguaje que articulara la realidad desde un lugar ajeno a la censura y la violencia. En ese sentido, la poesía cumplió este objetivo.

\section{A manera de conclusión}

A manera de conclusión, diremos que la poesía latinoamericana de la segunda mitad del siglo XX se desarrolla en un contexto cuya complejidad está dada por múltiples procesos sociales y políticos. Uno de los más significativos son las dictaduras militares que se instauraron en un buen número de países sudamericanos y centroamericanos, aunque para este trabajo abordamos específicamente el caso chileno. Es claro que en un contexto político tan complejo, una nómina importante de artistas de la época hizo de sus obras un espacio de crítica frente a la violencia imperante, lo que trajo como consecuencia la proliferación de textos cuya preocupación principal era incorporar el tema social como elemento estructural. En ese sentido, buena parte de los escritores durante la dictadura chilena, asumieron un compromiso político y estético con la convicción de que el acto poético es también político, por lo que su obra tiene una incidencia en la transformación de la sociedad.

Revisar algunos de los episodios más significativos de la vida artística en el Chile bajo dictadura, resultó sin duda una tarea compleja, dado que el panorama es vasto y las referencias son diversas. Dos ejemplos concretos son la Escena de Avanzada y el colectivo CADA -que por sí solos ameritan un trabajo exhaustivo-, para efectos de este artículo consideramos aspectos generales que nos sirvieron para perfilar algunas de las características formales en las obras de Raúl Zurita y Carmen Berenguer, y mediante un análisis de los libros Canto a su amor desaparecido y Huellas de Siglo, evidenciamos que la poesía escrita en contextos de violencia es un discurso válido que asume la realidad como un hecho problemático y decide manifestarlo en el poema. Esto mediante los recursos literarios adecuados para representar las estrategias de memoria-olvido y una resignificación del hecho histórico.

Si bien la revisión anterior es una retrospectiva un tanto general de un momento complejo en la vida de Chile, aspira a ser también una posible ruta de lectura que se sitúa en el presente, dado que los dos autores aquí analizados son un referente fundamental para la poesía reciente en Latinoamérica. La obra de Zurita como la de Berenguer fue desde el momento de su aparición hasta la fecha, un cuestionamiento frontal a la realidad chilena y al quehacer poético mismo; recordemos que la reflexión y praxis de la Escena de Avanzada fue una fuerza disruptiva en medio de una sociedad reprimida por la violencia. Así entonces, los lenguajes 
producto de esta reflexión tenían que poseer la capacidad de nombrar y acaso enfrentar desde la imaginación y la inteligencia al poder del Estado.

La obra de estos dos autores nos plantea una serie de interrogantes que es posible desentrañar en la medida que analicemos el fenómeno de modo integral, es decir, considerar que la poesía y, en términos generales, la literatura de este periodo echaron mano de la interdisciplinariedad para nombrar de otro modo lo sucedido. Eso explica que, por ejemplo, Raúl Zurita trascendió la página y los soportes tradicionales para expresarse en otras materialidades. El caso de Berenguer es también peculiar si consideramos las maneras tan inteligentes a través de las cuales ha jugado con las nociones de género literario y de performance. Estos cruces disciplinares han arrojado resultados sumamente interesantes en la poesía latinoamericana reciente, pues se ha apostado por escrituras que cuestionan su realidad, o dicho de otro modo, estamos frente a una poesía indócil que reflexiona sobre sus circunstancias sociales, políticas y estéticas. Lo que en modo alguno es un ejercicio menor, pues en mucho es herencia de aquellas escrituras que surgieron en contextos de violencia, tal es el caso de los revisado a lo largo de este trabajo.

\section{Referencias}

Aguilera López, Jorge. (2012). Perspectivas latinoamericanas contemporáneas del compromiso político en poesía. En Carlos Huamán (Ed.), América diversa. Literatura y memoria (pp. 77-89). Perú: Altazor.

Berenguer, Carmen. (2018). Obra poética. Chile: Editorial Cuarto piso.

Bürger, Peter. (1987). Teoría de la vanguardia. Barcelona: Ediciones Península.

Cárcamo Huechante, Luis. (2016). La ciudad neoliberal y un habla rebelde: isomorfismos y voceos en Huellas de siglo de Carmen Berenguer. En Juan Pablo Sutherland (Ed.), Cuerpos y hablas disidentes en la poesía de Carmen Berenguer (pp. 61-62). Chile: Mago Editores.

Carrasco, Iván. (1989). Poesía chilena de la última década (1977-1987). Revista chilena de literatura, 33, 67-98.

Comisión Nacional de Verdad y Reconciliación. (s. f.). Informe de la Comisión Nacional de Verdad y Reconciliación (Informe Rettig). Recuperado de http://bibliotecadigital.indh.cl/handle/123456789/170

Del Valle, Rosamen. (2001). La visión comunicable: Antología poética. Madrid: Signos Huerga y Fierro Editores.

Espinosa, Julio. (2008). Antología del siglo XX en Chile. Chile: Visor.

Faundes, Juan Jorge. (2014). Poesía revolucionaria chilena. Desde el sacrificio de Allende a la resistencia poética. Chile: Ocean Sur.

Leskinen, Auli. (2007). Huellas de Eros y Thánatos en la narrativa de Diamela Eltit. La palabra en movimiento en el juego entre tropos, metáforas y deconstrucciones lingüisticas. (Tesis de doctorado en Estudios Latinoamericanos). University of Helsinky, Finlandia. Recuperado de https://helda.helsinki.fi/bitstream/ handle/10138/19194/huellasd.pdf?sequence=1\&isAllowed =y 
Ludmer, Josefina. (2009). Literaturas posautónomas. Propuesta Educativa, 32, 41-45. Recuperado de http://www.redalyc.org/ pdf/4030/403041704005.pdf

Memoriachilena Biblioteca Nacional de Chile. (s. f./a). Primer Comunicado de la Junta de Gobierno. Recuperado de http://www.memoriachilena.cl/602/ w3-article-92134.html

Memoriachilena Biblioteca Nacional de Chile. (s. f./b). Revista La Bicicleta (1978-1990). Recuperado de http://www.memoriachilena.gob.cl/602/ w3-printer-100795.html

Morales, Andrés. (2010). Antología poética de la generación del ochenta. Chile: Editorial Imago.

Moraña, Mabel. (2014). Inscripciones criticas. Ensayos sobre cultura latinoamericana. Chile: Editorial Cuartopropio.

Osorio Ureta, Valeria. (2012). Tortura en la dictadura chilena: la segregación de la anestesia. Revista Sociedad y equidad, 3(1), 239-248.

Reyes Sánchez, Rigoberto. (2012). Arte, politica y resistencia durante la dictadura chilena: del C.A.D.A. a Mujeres por la Vida. (Tesis de doctorado en Estudios Latinoamericanos). Universidad Nacional Autónoma de México, México. Recuperado de http://132.248.9.195/ ptd2013/julio/0697639/Index.html

Richard, Nelly. (2007). Márgenes e Instituciones. Arte en Chile de 1973. Chile: Ediciones Metales Pesados.

Salazar, Yovany. (2015). Representación del sujeto emigrante como el otro en la novelística ecuatoriana. Revista San Gregorio, 1(9), 22-33.

Staude, Sergio Carlos. (2011). El duelo: sus recursos. Desde el jardin de Freud, 11, 181-186. Recuperado de https://revistas.unal.edu.co/index.php/jardin/ article/view/27242/39966

Villegas Aguilar, Patricia. (2007). Poesía y memoria. México: Universidad Iberoamericana.

Zac, Lilian. (1995). The narratives of order: the discourse of the Argentinean military regime (1976-1983). (Tesis de doctorado en Letras). University of Essex, Colchester, United Kingdom.

Zurita, Raúl. (1985). Canto a su amor desaparecido. Chile: Editorial Universitaria.

Zurita, Raúl. (2018). Un mar de piedras. Chile: Fondo de Cultura Económica.

\section{Notas}

2 Para este trabajo nos ceñimos estrictamente al marco temporal que abarca la dictadura militar en Chile (1973-1990), aunque no podemos dejar de reconocer que son múltiples los trabajos que revisan de manera crítica los años previos al golpe y los de la transición a la democracia.

3 Los acercamientos a las distintas tendencias poéticas de la época (dictadura militar) son diversos, además de que cada investigador plantea los conceptos que mejor sirven a sus fines. La clasificación hecha por Iván Carrasco resume de buena manera las líneas más representativas de la poesía de las décadas de 1980 y 1990, es por ello que nos ceñimos a esta clasificación para revisar las estrategias literarias de los dos autores que en este trabajo analizaremos, Carmen Berenguer y Raúl Zurita. 
"El rol que desempeñó la publicación periódica [...] fue como gestor protagónico de diversas actividades que impulsaron la rearticulación cultural del país, como, por ejemplo, concursos y festivales que sirvieron de plataforma para narradores, poetas y artistas que daban sus primeros pasos. Pero, por sobre todo, el principal aporte que realizó La Bicicleta fue el de estimular a la juventud de la época a tomar conciencia de la realidad social que entonces se vivía, a través de la difusión y la gestión cultural" (memoriachilena Biblioteca Nacional Digital de Chile, s. f/a., párr. 5).

5 Además de los grupos arriba apuntados, es importante señalar que un buen número de artistas, críticos y poetas engrosaron las filas de esta nueva manera de pensar y hacer arte. Entre los nombres más destacados figuran los artistas: Juan Dávila, Virginia Errázuriz, Francisco Brugnoli, Gonzalo Díaz, Arturo Duclós, Claudia Donoso, Carlos Gallardo y Víctor Hugo Codocedo. Los narradores y poetas, Enrique Lihn, Diego Maquieira, Gonzalo Muñoz, Juan Luis Martínez, Carmen Berenguer y Marcela Serrano. Las críticas Adriana Valdés y Eugenia Brito, además de los filósofos Patricio Marchant y Pablo Oyarzún.

6 La Escena de Avanzada surgió sobre todo de las artes visuales y sus principales exponentes fueron Carlos Leppe, Eugenio Dittborn, Catalina Parra, Carlos Altamirano, el grupo CADA, Lotty Rosenfeld, Juan Castillo, Juan Dávila, Víctor Hugo Codocedo, Elías Adasme, entre otros. Nelly Richard señaló que también la literatura y la filosofía jugaron un papel importante en el movimiento, de tal manera que: "las textualidades poéticas y literarias de Raúl Zurita y Diamela Eltit, fueron importantes en la Escena de Avanzada que conjuntó a una constelación de voces críticas de la que participaron filósofos y escritores como Ronald Kay, Adriana Valdés, Gonzalo Muñoz, Patricio Marchant, entre otros" (Richard, 2007, p. 15).

7 Se recomienda la lectura de la tesis de Rigoberto Reyes Sánchez titulada Arte, politica y resistencia durante la dictadura chilena: del C.A.D.A. a mujeres por la vida (2012), dado que este trabajo es una investigación puntual y detallada sobre los objetivos y métodos particulares que siguió el colectivo de arte.

8 Recordemos que Raúl Zurita es de los miembros fundadores del grupo CADA.

9 El treno (del griego thrênos, lamento) es una composición de la lírica griega arcaica. Lamento fúnebre destinado a ser ejecutado por un coro con acompañamiento musical. Se cantaba en ausencia del muerto. Los trenos más conocidos son los de Píndaro y Simónides, que suelen utilizar el lamento por el muerto como punto de partida para la reflexión moral sobre el destino humano.

10 En virtud de ello el Informe Rettig señala que, según la Comisión de Verdad y Reconciliación (s. f., p. XIX), la violación a los derechos humanos se define como "aquellas situaciones de detenidos desaparecidos, ejecutados y torturados con resultado de muerte en que aparece comprometida la responsabilidad moral del Estado por actos de sus agentes, de personas a su servicio o por particulares bajo pretextos políticos".

11 Este libro, impreso de manera artesanal, fue un homenaje al poeta y revolucionario irlandés Bobby Sands, quien falleció después de una prolongada huelga de hambre bajo el régimen británico de Margaret Thatcher, y que dejó un diario de vida estremecedor, en el que definió sus causas de lucha y la dignificación de su resistencia a la dominación inglesa. Por otra parte, a través de la figura del poeta irlandés, Carmen Berenguer realiza un homenaje a los prisioneros políticos que luchan por reivindicar la situación sociopolítica de su país.

12 El investigador Luis E. Cárcamo-Huechante señala que buena parte del léxico ocupado por Carmen Berenguer, al menos en la primera sección del libro, nos ingresa de golpe a la economía lingüística de la urbe capitalina en el Chile de fines del siglo XX, una ciudad marcada por el flujo y circulación de signos disparatados. Como disparos, como balazos irrumpe una seguidilla de palabras 
en inglés y luego alemán antes de dar paso al castellano. Pero, también se evoca el golpeteo musical de las bandas de música punk y el estilo heavy metal de la época. Se superponen así las lenguas de las estéticas alternativas y underground que movilizan los cuerpos juveniles y contestatarios; pero también son lenguas evocativas de colonialismos e imperialismos culturales, económicos y políticos de guerras y poderes bélicos (Cárcamo-Huechante, 2016, pp. 61-62).

\section{Notas de autor}

1 Mexicana. Doctora en Letras por la Universidad Nacional Autónoma de México (UNAM), México. Programa de Becas Posdoctorales en la UNAM, Becaria del Centro de Investigaciones sobre América Latina y el Caribe (CIALC), asesorada por el doctor Carlos Huamán López. Correo electrónico: evacbarrera@hotmail.com 